ISSN: 1130-2887 - eISSN: 2340-4396

DOI: https://doi.org/10.14201/alh.23889

\title{
LA OIT Y LA DEFINICIÓN DE AMÉRICA LATINA COMO REGIÓN DE CARÁCTER ESPECIAL: EL PROGRAMA INDIGENISTA ANDINO ENTRE LA CUESTIÓN INDÍGENA Y LA MODERNIZACIÓN UNIVERSALISTA \\ The ILO and the Definition of Latin America as a Region of Special Concern: the Andean Indian Programme between the Indigenous Question and Universalist Modernization
}

\author{
Juan MARTÍN SÁNCHEZ @i jmartinsanchez@us.es ${ }^{1}$ \\ Martin BREUER (D) martin.breuer@uni-bielefeld.de ${ }^{2}$ \\ ${ }^{1}$ Universidad de Sevilla \\ ${ }^{2}$ Universität Bielefeld
}

Envío: 2020-08-25

Aceptado: 2021-06-10

First View: 2021-08-17

Publicación: 2021-08-31

RESUMEN: Este artículo estudia cómo la OIT en tanto organización burocrático-política internacional dio forma a la representación de América Latina como una región del mundo diferenciada de la «norma» histórica de las sociedades modernas. En particular, se analiza cómo el Programa Indigenista Andino (PIA) reelaboró y amplificó tres aspectos recurrentes en la contribución de los Andes a la representación de América Latina: el carácter regional, la reivindicación indigenista y la novedad experimental.

Palabras clave: Organización Internacional del Trabajo; América Latina; representación; indigenismo; desarrollo

ABSTRACT: This article studies how the ILO as a bureaucratic and political apparatus shaped the representation of Latin American as a world region differing form the historical «norm» of modern societies. In particular, it analyzes how the Andean Indian Program (PIA) reworked and amplified three recurrent aspects in the contribution of the Andes to the representation of Latin America: the regional character, the indigenist claim and the experimental novelty.

Keywords: International Labor Organization; Latin America; Representation; Indigenism; Development 


\section{INTRODUCCIÓN ${ }^{1}$}

La representación colectiva de América Latina como región específica en el mundo contemporáneo es un fenómeno sociohistórico de gran interés académico, social y político. El propio nombre de América Latina ha estado en las discusiones, los proyectos y las luchas políticas ${ }^{2}$. Pero no solo se trata de un nombre, sino del conjunto de caracterizaciones, comparaciones y narrativas que se asocia a ese nombre de manera icónica, y cuya eficacia, según Bourdieu (1985), depende del poder social, burocrático y político que tengan los actores que lo impulsan, al mismo tiempo que el poder de esos actores depende de la incorporación de ese conjunto icónico a la propia constitución social de las sociedades representadas. En este artículo nos preguntamos por la capacidad que la Organización Internacional del Trabajo (OIT) tuvo para implementar una representación de América Latina como conjunto de sociedades alejadas de la «norma» histórica de las sociedades modernas.

Queremos continuar con una tesis lanzada por Rossana Barragán (2017) dentro de un libro sobre la historia de la OIT en América Latina. Según esta, entre los efectos indirectos de esa historia estuvo la contribución de la OIT a una representación regional diferenciada, una especie de geografía imaginada en los términos de Edward Said (2008). Apunta a dos aspectos importantes de esa representación: a) al enmarcado de toda la región como geografía afectada por la «cuestión indígena», algo que afecta a los indígenas y al resto de trabajadores y ciudadanos; y b) a la tensión entre la definición universalista de la OIT y la práctica de una geografía humana parcial dentro de esa universalidad. Se podría decir que la llamada «cuestión indígena», planteada como cuestión «especial», se transformó en global para América Latina, mientras que el proyecto «universalista» de la OIT se desarrolló de manera parcial y sesgada en el subcontinente. En este artículo, desarrollamos esta tesis en el análisis del Programa Indigenista Andino (PIA), como caso ejemplar de imbricación entre la proyección simbólica y la práctica burocrático-política. Este consistió en un programa de asistencia técnica de la Organización de Naciones Unidas (ONU), liderado por la OIT, que pretendía mejorar las condiciones de vida de los indígenas de los Andes y su integración en las sociedades nacionales. Su historia desborda las fechas concretas del programa en Bolivia, Ecuador, Perú, Argentina, Chile, Colombia y Venezuela, de 1953 a 1972 (Rens, 1987), y encabalga los años veinte y treinta con las décadas de la Guerra Fría.

Hemos privilegiado el análisis directo de las fuentes producidas, ordenadas y presentadas por la propia OIT. Somos conscientes de los riesgos de sesgo que esto crea, aunque lo hemos tratado de controlar con una amplia revisión bibliográfica (que excede en mucho la citada), con el análisis de la recepción que el PIA tuvo en la prensa y en la academia durante su realización y con la inserción del PIA en la historia social e institucional más amplia de la OIT en América Latina. También hemos revisado los repositorios del Instituto Indigenista

1. Este artículo es parte del Proyecto HeterQuest «La heterogeneidad en cuestión: saberes y prácticas cruzadas en el derecho, el indigenismo y lo social. Mesoamérica y área andina, época contemporánea» (PID2019-107783GB-I00 / AEI / 10.13039/501100011033).

2. Sobre la aparición y consolidación del término «América Latina» como nombre para todo el subcontinente, Quijada (1998) y Gobat (2013). 
Interamericano (III), los dispersos restos del Instituto Indigenista del Perú y la documentación que guardan las bibliotecas de la Universidad Católica de Perú y del Instituto de Estudios Peruano. Adoptamos una perspectiva interpretativa próxima a Umberto Eco (1998), distinguiendo entre la selección y el análisis de las fuentes y su uso en la argumentación. Sin otras adscripciones, nos situamos en la historia y la sociología de las representaciones y los campos sociales ${ }^{3}$.

Seguimos una noción dual de representación social colectiva: a) como trama de acciones interdependientes «en nombre de» ciertos colectivos o sociedades, que esas mismas acciones suplen y constituyen; b) el registro, en discursos y figuras cognitivas de diverso formato (textos, imágenes, lugares...), de las luchas por el valor representacional de esas acciones. Para atender a la sobredeterminación mutua de ambos aspectos y al solapamiento de las estrategias políticas en los diversos niveles temporales y espaciales de las sociedades a estudiar, ordenamos nuestro argumento en tres apartados: primero abordamos la noción de «norma» histórica y cómo la OIT proyecta, con el PIA, esta norma en los Andes y América Latina. Luego, contrastamos el discurso y la práctica de tres aspectos centrales del PIA: la categorización de los indígenas como colectivo especial a proteger, la definición regional de los Andes a partir de la presencia indígena y la concepción del proyecto como experimento de política integral. Por último, reevaluamos el PIA como trama de acciones interdependientes, ambiguas y conflictivas, con efectos simbólicos sobre el conjunto de América Latina.

\section{LA OIT EN LA «NORMA» HISTÓRICA Y EL PIA EN LA METONIMIA ANDINA}

En torno al centenario de la fundación de la OIT en 2019, se están publicando una importante serie de estudios que muestran su muy variada y amplia labor (Maul, 2019). Las investigaciones referidas a la acción de la OIT en América Latina (Caruso y Stagnaro, 2017; Herrera León y Herrera González, 2013; Weinberg, Martín-Sánchez, Martín-Sánchez y Giraudo, 2020; Breuer, 2018b) subrayan que se trató de una historia abierta, una concurrencia de actuaciones interdependientes en la que los distintos actores (gobiernos, sindicatos y patronales, los directivos de la OIT y sus expertos «técnicos», los grupos de la sociedad civil o la académica, etc.) estaban construyendo el moderno campo de las relaciones internacionales, del que los países latinoamericanos eran fundadores por más que estuvieran en una posición secundaria respecto de las pocas grandes potencias del mundo. Una nueva sociedad internacional que, tras la Segunda Guerra Mundial (Kott, 2018b), estaría protagonizada por los conflictos de las descolonizaciones y la consolidación de la Unión Soviética y China como antagonistas de las sociedades capitalistas ${ }^{4}$. En esta perspectiva, organismos como

3. Entre otros autores: R. Koselleck, P. Bourdieu, R. Castel, N. Elias, H. F. Pitkin y M. Quijada.

4. En los años ochenta, el escenario internacional cambiará de nuevo, antes de 1989, con la participación de países y protagonistas surgidos de la descolonización, algo que afectó la propia historia de la OIT 
la OIT son actores institucionales que actúan como sujetos político-burocráticos y tejen su trama en órganos ejecutivos y deliberativos; en comisiones especializadas y conferencias internacionales; en revistas, informes técnicos y libros; en la promulgación de normas y resoluciones; en su contabilidad, etc. Pero también se van convirtiendo en instituciones que ordenan las experiencias y las expectativas de los campos sociales, como el indigenismo o la cooperación al desarrollo, instituciones que, además, cobijan y promueven el desarrollo de asociaciones y actividades autónomas, como las reuniones «científicas», los sindicatos o las ONG, al mismo tiempo que contribuyen al reparto geopolítico de las sociedades contemporáneas. La constitución tripartita (gobiernos estatales, sindicatos y empresarios), junto a la oficina ejecutiva, hacen de la OIT un actor compuesto y una institución social de múltiples escenarios, lo que le permite simultanear la actuación global de los órganos de dirección con las acciones parciales que desarrollan las comisiones especializadas y las oficinas regionales.

Desde esa estructura compuesta, la OIT combinó el desarrollo de un modelo de relaciones laborales y de «justicia social» basado en las estructuras sociales más industrializadas de Europa y Norteamérica (Kott, 2018a) con la regulación del trabajo «atípico», como el agrícola no salarial, el nocturno, el de mujeres y niños, el de marinos mercantes, el trabajo forzado y el de poblaciones bajo control colonial. Esta combinación articulaba, de manera inestable, un proyecto normalizador dentro de las sociedades y entre los países en torno a la «condición salarial» (Castel, 2004), con situaciones y estructuras sociales que «resistían»a ese nuevo orden industrial, urbano e internacional. Ese modelo conllevaba una descripción normativa (Estado regulador, trabajo masculino formalizado, empresa racionalizada, familia nuclear, consumo estandarizado, derecho del trabajo y negociación colectiva, protección social y servicios públicos) y una noción del cambio en términos «civilizatorios». Esa es la norma histórica a contrastar dentro de los «países desarrollados», que rara vez la cumplieron plenamente y en las «sociedades subdesarrolladas».

En el Tratado de Versalles de 1919, la OIT se proclama valedora internacional de esa concepción teleológica de la justicia social que implicaba la normalización socioeconómica. Antes de que la teoría de la modernización compactara esa norma histórica en un modelo de sistemas funcionales, capital humano e integración cultural, la OIT ya disponía de discursos prácticos sobre la historia, la formación, el derecho, la economía y las instituciones en términos de evolución civilizatoria ${ }^{5}$.

En América Latina, la OIT ha trabajado desde ese proyecto que está en su origen y se reelaboró en la Declaración de Filadelfia de 1944, pese a entender que las sociedades de la región presentaban rasgos sociales e históricos alejados del patrón de países industriales desarrollados ${ }^{6}$. Debido a este contraste que dejaba a la propia OIT algo fuera de la región, a la necesidad de crecer frente a la opción panamericanista y a su estructura tripartita, la

(Maul, 2019) y las normas internacionales sobre pueblos indígenas (Anaya, 2009).

5. Basta con revisar los contenidos de la Revista Internacional del Trabajo para tener una síntesis plural de la historia intelectual y práctica de la OIT.

6. Las fuentes sobre este entendimiento son abrumadoras. 
OIT concertó su trabajo con los actores estatales y sociales que formaban las sociedades latinoamericanas. Ya en la primera Conferencia Internacional del Trabajo (CIT) en Washington 1919, en la que, de un total de 32 delegaciones nacionales, 13 eran latinoamericanas, estas tuvieron una actitud proactiva a favor de una representación colectiva basada en la cultura, las cuestiones sociales, el derecho, la indianidad y el mestizaje (Martín-Sánchez, 2017), un discurso consecuente con la renovación intelectual y política de las primeras décadas del siglo XX en América Latina, en la que los indigenismos y los nacionalismos confluyeron en torno a la «promesa» de una identidad compartida, ya fuera Euro-, Indo- o Latinoamérica (Devés, 2000).

Con matices y posiciones distintas, la OIT y las delegaciones latinoamericanas de gobiernos, sindicatos y empresarios coincidían en la necesidad de actuar a favor de la expansión del mundo industrial moderno en la región, a la que se consideraba atrasada económica, cultural y políticamente 7 . Pero, al mismo tiempo, debían atender a ciertos asuntos que distinguían a los países latinoamericanos, entre los que, muy pronto, estuvieron las «condiciones de vida y trabajo de los indígenas» ${ }^{8}$. Para responder a esta demanda sobre la llamada cuestión indígena, la OIT se embarcó en una reelaboración parcial del indigenismo latinoamericano, que mejoró su posición en la región y que definió el protagonismo que ha ganado en el campo indigenista internacional.

La dirección de la OIT adaptó las demandas latinoamericanas a su proyecto de justicia social y a su modelo burocrático de actuación, incluyendo las conferencias de países americanos y la puesta en marcha de comisiones especializadas. En esa historia, las Conferencias de países americanos miembros de la OIT (Santiago de Chile 1936, La Habana 1939, México 1946 y Montevideo 1949) fueron construyendo una doble vía sobre las poblaciones indígenas de América Latina, que se sumarían al debate más general sobre "poblaciones indígenas» en países dependientes e independientes ${ }^{9}$. Por una parte, estaban las encuestas sobre condiciones de vida y protección de los trabajadores indígenas, encaminadas a la adopción de instrumentos de derecho internacional, como ocurrió en 1957 con el Convenio 107, sobre poblaciones indígenas y tribuales, y la Recomendación asociada $104^{10}$. La otra vía buscaba un conocimiento experto para la ejecución de programas de mejora de las condiciones de vida y la integración social de los indígenas. En esta se inscriben el PIA, la comisión de expertos que lo diseñó y las negociaciones con los gobiernos de Bolivia, Perú y Ecuador para su puesta en marcha. Las dos vías, la reguladora y la ejecutiva, se combinaron y reforzaron mutuamente, pero también tuvieron desarrollos paralelos según sus lógicas

7. En perspectivas complementarias: Escobar (2012), Arrighi y Silver (2001).

8. Ya en el informe de Poblete Troncoso (1928) aparecía el relato histórico de reivindicación de culturas preconquista y de la legislación indigenista.

9. En los debates sobre el tema en la CIT de Montreal, 1946, las delegaciones latinoamericanas marcaron distancia respecto a propuestas que trataban de universalizar los diagnósticos realizados sobre las poblaciones indígenas en países dependientes.

10. En esta vía, se realizaron varios informes sobre condiciones de vida y trabajo de poblaciones indígenas y fue un asunto habitual en los debates de las Conferencias Internacionales del Trabajo. En 1953 se publicó la síntesis programática de la OIT sobre poblaciones indígenas con amplia información aportada por un numeroso conjunto de países en que destacaban los latinoamericanos (OIT, 1953). 
predominantes: por una parte, la concertación de normas internacionales y, por otra, la negociación entre gobiernos nacionales y las diversas estructuras de la OIT para la gestión cooperativa y experta del cambio social. Ambas vías fueron abordadas por las tensiones estratégicas entre soberanías nacionales, potencias regionales e internacionales y procesos de estandarización.

En una mirada retrospectiva algo sesgada, desde los años noventa, se destaca el papel del derecho internacional como gran aporte de la OIT sobre indígenas y América Latina, pero en los años cincuenta y sesenta fue el PIA el que tuvo protagonismo ${ }^{11}$. Desde entonces ha sido referencia habitual en la literatura sobre antropología aplicada, derecho indígena, desarrollo e indigenismo en América Latina. En los últimos años, ha sido objeto central de algunos estudios entre los que destacan los trabajos de Maurel (2012), Guthrie (2015) y la compilación de Prieto (2017). Esta última contiene un detallado análisis del desarrollo del PIA en Ecuador, Bolivia, Perú y Chile, con especial atención al papel de las mujeres y una interesante interpretación de conjunto, especialmente en el primer capítulo de Prieto y Páez (2017a), sobre el conflictivo ensamble entre la OIT y los gobiernos latinoamericanos que estaban desarrollando sus propias administraciones indigenistas.

El trabajo de la Comisión de Expertos en Trabajo Indígena, reunida por primera vez en La Paz, Bolivia, en enero de 1951, fue la base del PIA, que se reelaboró en el nuevo marco institucional de la ONU y del creciente campo indigenista interamericano (Giraudo, 2011). De la reunión en La Paz surgió la «Misión indigenista andina» (Misión Andina), con el objetivo de planificar un proyecto regional, multilateral e integral de cooperación técnica de la ONU hacia los Estados andinos y sus políticas de protección e integración de la población indígena. Trabajó de junio de 1952 a enero de 1953 y estuvo compuesta por 11 miembros y 3 asesores, representando a la ONU, la OIT, la UNESCO, la OMS y la OAA, procedentes de 9 países distintos y de varias áreas de conocimiento (Misión Andina, 1953, pp. 6-7). No se puede concluir que fuera un comité especialmente «indigenista», pero sí que el proyecto que presentó lo era. En conjunto, la Misión construía una representación colectiva programática basada en el diagnóstico de los problemas comunes a los indígenas, en su ubicación en la región andina y en las expectativas de cambio social ${ }^{12}$.

Pero para dar un sentido más general al PIA y su relevancia en la representación que la OIT hacía de América Latina, nos interesa una conferencia de Jef Rens (1959) (director general adjunto de la OIT) en la Casa de los Trabajadores de Caracas, el 23 de marzo de 1959. El texto hace balance de la colaboración entre la organización y la región. Al comentar los inicios de la OIT, Rens subraya la convergencia de «aspiraciones históricas» (Rens, 1959, p. 3) y la profunda impresión que tuvo en Albert Thomas su viaje por el Cono Sur en 1925:

Asombrado por la inmensidad y la belleza de aquellos países, sobrecogido por las miserias y las injusticias que vieron sus ojos y conmovido por la voluntad evidente de numerosos políticos y

11. Véanse los diferentes informes del «Panel of Consultants on Indigenous and Tribal Populations» de la OIT de octubre de 1962 (Archivo OIT Ginebra, PCITP/1962). También sorprende que sea el PIA uno de los pocos hechos latinoamericanos que la propia OIT destaca en su propia historia: https://www. ilo.org/100/en/story.

12. Un detallado análisis de la Misión y del proyecto en Prieto y Páez (2017a). 
dirigentes de las organizaciones profesionales de cambiar el curso de los acontecimientos, adquirió la convicción de que la Organización Internacional del Trabajo podría desempeñar una misión fundamental en el desarrollo armonioso de estos países. (Rens, 1959, p. 4)

Aquel asombro dibujaba una parcialidad en el proyecto universalista de la OIT, algo que Harold Butler, el segundo director general de la OIT, integró en un nuevo horizonte de expectativas políticas y burocráticas al promover las conferencias americanas del trabajo. Rens citaba un párrafo del informe de Butler ante la CIT de 1935:

Está fuera de duda que existen, de la competencia de nuestra Institución, cuestiones de carácter menos universal que otras, por afectar principal o exclusivamente a una región geográfica o a un grupo determinado de países. En todo caso, ningún precepto constitucional se opone a la convocatoria de reuniones especiales en las que se examinen y discutan esas cuestiones por aquellos países más directamente interesados en ellas y bajo los auspicios de la Organización. (Rens, 1959, p. 6. Cursiva del autor)

La propuesta de Butler estaba creando un marco para una representación colectiva compuesta, ya no en términos corporativos (gobiernos, patronales y sindicatos), sino según la naturaleza especial de los asuntos, el ámbito geográfico y el diseño de políticas parciales. Esto le permitía a Rens argumentar a favor de la colaboración entre países latinoamericanos y la OIT como un juego entre actuaciones particulares y proyectos universales.

El PIA cumplía con ese marco, convirtiéndose en metonimia de esa colaboración. Rens estaba señalando las muchas facetas de la relación entre la OIT y los países latinoamericanos y sabía que el PIA tenía una muy limitada eficacia en el cambio estructural de estos países. Pero ponía la preocupación indigenista al mismo nivel que la ayuda a la industrialización y lo hacía en una retórica a favor del proceso civilizatorio, en el que no faltaban adjetivos paternalistas y condescendientes respecto de los indígenas, el mundo rural tradicional y las dificultades de las sociedades latinoamericanas. El PIA no inventaba una representación colectiva basada en una geografía exótica, unos pueblos especiales y una historia experimental, estos eran elementos que se venían construyendo desde mucho antes, pero frente a otras cuestiones más recientes, como los seguros sociales o la libertad sindical, sí participaba del poder simbólico de esa representación dominante, dentro y fuera, de América Latina como «geografía imaginada»: especial y exótica, soberana y dependiente, original y colonizada, tradicional e innovadora, natural y humana. Esa representación le permitía a Rens inscribir la labor de la OIT en el largo recorrido de la emancipación latinoamericana y citar al socialista peruano José Carlos Mariátegui o concluir con una «profecía» de Simón Bolívar: «Ya la veo mi Patria, sentada sobre el Trono de la Libertad, empuñando el cetro de la Justicia, coronada por la Gloria, mostrar al mundo antiguo la majestad del mundo moderno» (Rens, 1959, p. 29. Cursiva del autor).

El discurso de Rens para legitimar el trabajo de la OIT en América Latina tomaba los efectos por causa, al situar al PIA como razón de la colaboración entre ambas partes, cuando era un conjunto de arreglos pragmáticos en un marco simbólico amplio. Hasta cierto punto, ese discurso metonímico anticipaba el concepto de Americanity que Aníbal Quijano y Immanuel Wallerstein propusieran en 1992. En este, la categorización étnica y racista de 
los indígenas, la definición colonial de la geografía y la novedad como historia experimental son procesos que insertan a América en el mundo moderno a la vez que representan la modernidad.

\section{LOS TRES RETOS DE LA REPRESENTACIÓN AMERICANA DEL PIA}

Cuando, el 27 de mayo de 1953, el Comité de Asistencia Técnica de las Naciones Unidas en el marco del Programa Ampliado de Asistencia Técnica ${ }^{13}$ aprobó el PIA, apenas era un proyecto, con amplias referencias simbólicas y prácticas, para negociar los encajes políticos, burocráticos y técnicos que todas las partes sabían necesarios ${ }^{14}$. Con cambios en el lenguaje y los referentes teóricos, el nivel simbólico se mantuvo durante el programa y permaneció como representación histórica, mientras que las realizaciones efectivas quedaron como registros del poder que el PIA alcanzó. En este apartado, mostramos esta labor doble de representación simbólica y práctica en torno a sus tres mayores retos: la integración de los indígenas, la demarcación regional y la política como experimento.

La Misión Andina (1953, p. 14) se preguntaba: «¿Quiénes son los indígenas y cuáles son sus problemas?». Aunque se dice que «Los pueblos indígenas de la región andina constituyen la gran mayoría de la población rural», el informe asume que «Es imposible dar una definición precisa en que se separa a los indígenas andinos de los no indios con quienes conviven» (Misión Andina, 1953, p. 15). No recurre a un análisis de instituciones y estructuras sociales, culturales y políticas en que se definieran las posiciones sociales que identifican a los indígenas, sino que opta por una caracterización basada en atributos sociales, llamados «denominadores comunes». Adopta diez criterios: distribución de la población indígena, idiomas, comunidad y tierra, métodos agrícolas y productividad, comercialización de productos, salubridad e higiene, infancia e instrucción, religión, relaciones con los no indios y participación política. En estos, se enfatizan los supuestos atributos idiosincráticos (psicología, carácter cultural, apego al terruño, a la vida comunal, la desconfianza a los no indios, la lengua, etc.) y se llega a un cierto «lugar común» que confirma la representación estereotípica que ya se tenía al inicio de la Misión, la del «indio» como «los habitantes de la región que no están «integrados»»» social, económica, cultural y políticamente en sus respectivas sociedades nacionales. Si bien se subraya que «Indio», en los países andinos, no tiene una significación racial estricta» (Misión Andina, 1953, p. 15) ${ }^{15}$, se desarrolla una historia natural de largo recorrido (cinco siglos), en la que se subraya la conservación «excepcionalmente inalterada [de] su forma de vida tradicional, a pesar, o tal vez a causa, del trato diferente y la explotación de la que han sido objeto» (Misión Andina, 1953, p. 16). Eso sí, esa historia

13. El EPTA (siglas en inglés) fue lanzado por la ONU en 1949 y es el predecesor del Programa de Naciones Unidas para el Desarrollo (PNUD) creado en 1965 (Jolly et al., 2004).

14. Prieto y Páez (2017b) utilizan la idea de «ensambles estatales», con ecos de la noción de Embedded Autonomy de Peter Evans.

15. El libro de Poblete Troncoso (1938) tenía más referencias racistas, pero sus descripciones eran más amplias, estructurales y menos orientadas por una historia natural de atributos intrínsecos. 
estaba por cambiar y la ayuda técnica del PIA podía reducir los costos de la transición al mundo moderno.

En paralelo a la caracterización de los indígenas andinos, estaba la caracterización de la región que ese componente «indígena» dotaba de continuidad geográfica, histórica, social, económica y política. Si el primer capítulo del informe de la Misión presentaba sus fundamentos, objetivos, composición, itinerario y método de trabajo, el segundo capítulo presentaba «El problema», y para delimitarlo comenzaba con un apartado sobre «Topografía, clima y recursos naturales». Se recurre a los mapas y a la caracterización de los muchos extremos naturales que constituyen la región: la profundidad de los valles y la altura de las montañas, las grandes y difíciles distancias, la altitud del hábitat, variabilidad extrema del clima, la fecundidad biológica, la riqueza minera, etc. En una breve y apretada representación de la geografía física y humana, los adjetivos antagónicos se suceden en una cartografía exótica, en la que «el indio ha trabajado durante siglos, como siervo o asalariado, desempeñando un importante papel mudo y a veces ignorado, para extraer las riquezas exportables de sus países» (Misión Andina, 1953, pp. 12-13) ${ }^{16}$. La fuerza simbólica de esta geografía natural dota al informe, a la labor de la Misión y al desarrollo del PIA de un marco natural que apenas requiere explicación, que, hasta cierto punto, suplanta la explicación sociohistórica del mundo humano que se quiere entender y transformar. Esta interpretación es consistente con el enfoque regional, en el que se definían problemas y soluciones comunes de la región, y con la concepción integral y sistemática del problema de la integración, en la que, debido a su complejidad, la gestión técnica lograba subordinar a la política.

Las soluciones que proponía el capítulo III del informe de la Misión eran consecuentes con esos dos elementos indisociables del diagnóstico: los indígenas andinos y los Andes indígenas. La Misión, primero, y el PIA, después, participaron de una representación performativa, en la que la mejora de condiciones de vida y la integración de los indígenas en sus sociedades nacionales pasaban por mejorar las infraestructuras humanas y territoriales: formación, salud, higiene, tecnologías, carreteras, colonización, escuelas, activismo comunitario, etc. Pero en el PIA eran conscientes de que los problemas en la financiación, los escasos proyectos pilotos, la burocracia desplegada, el compromiso político, la población directamente afectada e, incluso, los factores extrarregionales implicados llevarían a resultados muy moderados y parciales. En este sentido, subrayar el carácter experimental del PIA no era solo prudencia «científica», ante un asunto apenas conocido, o «técnica», por la novedad en los objetivos y los procedimientos para la integración social de los indígenas; era, sobre todo, un esfuerzo por enmarcar la discusión y sus efectos al margen de la política. Ese carácter de experimento -diseñado y ejecutado desde la diplomacia, el saber experto, la burocracia y la política de bajo presupuesto- es el tercer rasgo fundamental que el PIA añade a la representación colectiva de América Latina, una «identidad geosocial» (Quijano y Wallerstein, 1992) en la que es posible, y habitual, el diseño y la ejecución de la política como experimento. Este elemento simbólico va más allá de la contención técnica, para

16. Prieto y Páez (2017a) identifican el papel del antropólogo Alfred Métraux en la referencia al Imperio Inca como sustento de esa delimitación andina del PIA, discurso que ganó fuerza desde la arqueología y la etnohistoria, Stein (2010). 
interpelar a la representación de América como continente «nuevo», a la que apelaba Rens en su cita del discurso de Simón Bolivar ${ }^{17}$.

Desde ese marco, el primer reto era poner en marcha un proyecto complejo y sui generis, un experimento para el que se tenían los objetivos y parte de la metodología, pero con muchos temas por resolver, como la estructura de autoridad, los lugares concretos donde desarrollarlo, la contratación y formación del personal, la duración, etc. La lenta y desordenada comunicación entre los expertos de las bases de acción, la oficina regional del PIA en Lima, las burocracias nacionales y la sede central en Ginebra frenaba el trabajo. Mientras los expertos de la OIT criticaban a las administraciones nacionales por falta de capacidad organizativa y apoyo, estas criticaban a los expertos de la OIT por falta de capacidad de liderazgo y conocimiento de la región. Entre tanto, la OIT tenía dificultades para reclutar al personal técnico cualificado, nacional e internacional, lo que dificultaba el cumplimiento del plan inicial ${ }^{18}$.

Pese a ello, en 1959, el PIA tenía seis proyectos en funcionamiento ${ }^{19}$ y, en 1961, afectaba a unos 250.000 destinatarios, según la OIT ${ }^{20}$. Entre 1952 y finales de 1959, las organizaciones de la ONU invirtieron unos dos millones de dólares estadounidenses en el PIA, cifra que solo muestra parte de los gastos, especialmente los sueldos de los expertos de la ONU y el dinero para viajes y algunos gastos para materiales ${ }^{21}$. Además, el PIA logró expandirse a Chile, Argentina, Colombia y Venezuela ${ }^{22}$, y, para 1974, el gasto de las agencias de la ONU sumaba 7179000 dólares (Rens, 1987, p. 45). A esta cifra, hay que añadir el trabajo de los aparatos burocráticos de las organizaciones de la ONU en el PIA, así como los aportes de los gobiernos nacionales en sueldos a los expertos y trabajadores nacionales, en instalaciones, materiales, comunicaciones, etc.

Junto al gasto, habría que tener en cuenta que se actuó en diversos niveles políticos (local, nacional, regional e internacional), entre distintas organizaciones internacionales y varias áreas de trabajo experto, además de enfrentar revoluciones nacionales o crisis internacionales. Este proceso incorporó personalidades, como su primer director, Enrique Sánchez de Losada; promovió funcionarios, como el peruano Carlos D’Ugard (ministro de Trabajo en 1955, director regional del PIA y más tarde director de la Oficina Regional

17. La historiografía sobre este asunto es ingente y abarca desde la recogida de información, el diseño y la ejecución de las reformas del virrey Toledo en Perú en el siglo XVI hasta los continuos planes de reestructuración más o menos reformistas, revolucionarios o reaccionarios. Para la política como experimento, Lechner (1986).

18. «Second Progress Report for the Advisory Committee for the Andean Indian Programme» del 28.11.1953, Archivo de la OIT en Ginebra (File Series: TAP/AND, File Number: 3, Jacket Number 1).

19. Eran las bases en Chimborazo (Ecuador), Puno-Tambopata (Peru) y Pillapi, Playa Verde, Otavi y Cotoca (Bolivia); informe interno de la OIT sobre el estado el PIA «Plan for Consolidation and Transfer» de junio de 1960 (Archivo OIT Ginebra, Z-II-10-8-2).

20. La estimación de que las bases del PIA alcanzaron 250.000 personas aparece por primera vez en un reporte interno de la OIT preparado para negociaciones con la agencia estadounidense USAID (Archivo OIT Ginebra, TAP/A, 11-4-61, 4).

21. «Report to Technical Assistance Committee» de noviembre de 1958 (Archivo OIT Ginebra, GB, 140-TA-101_2/3/4, 1).

22. En estos países, el PIA no alcanzó el efecto que tuvo en los Andes centrales, pero sí alcanzaba las fronteras simbólicas del mundo inca. 
de la OIT); desarrolló organismos específicos para las bases de acción y para la gestión en cada país (Prieto y Páez, 2017a), y sirvió como base para la Oficina Regional de la OIT en América Latina y el Caribe ${ }^{23}$. Además, el intercambio entre los expertos y las administraciones nacionales en el marco regional del PIA influyó en los planes de desarrollo rural en los países participantes (Max-Neef, 1992) y sirvió de referencia empírica para el debate sobre derecho internacional que llevó al Convenio 107, de 1957 (Rodríguez-Piñero, 2005). Toda una hoja de servicios con la que avalar la experiencia frente a deficiencias y críticas.

El segundo reto era lograr esa asistencia técnica («apolítica» [Ferguson, 1990]) con carácter regional acorde con la noción geográfica y cultural del mundo indígena. Esto enfrentaba la diferenciación de los indígenas entre pueblos, comunidades, localidades y, especialmente, entre Altiplano y Amazonía $a^{24}$. Pero la mayor dificultad estaría en llevar las políticas estatales al mismo esquema de cooperación «técnica». La Revolución boliviana de 1952 evidenció la carga política del PIA y puso en tensión su carácter regional. Ese año, comenzaron las reformas electoral y agraria, afectando a la realización del PIA en un país prioritario (Guthrie, 2015), pero también en Ecuador y Perú.

El nuevo gobierno boliviano tenía gran interés en ampliar el PIA en el país, pues suponía contar con el apoyo técnico y político de la ONU en la reforma agraria ${ }^{25}$. Sin embargo, el director general de la OIT, David Morse, ordenó que las actividades no ocuparan tierras expropiadas, algo que contravenía la reforma agraria que estaba afectando a los terratenientes del país ${ }^{26}$. El gobierno boliviano entendió que se trataba de una intromisión en su soberanía nacional, lo que puso al PIA al borde de la cancelación en ese país ${ }^{27}$. El respaldo de los EE. UU. a la Revolución en Bolivia, con el aumento de su cooperación técnica en el país ${ }^{28}$, facilitó una solución de compromiso: que la primera base de acción, en la hacienda de Pillapi, cerca del Titicaca (Zabala Canedo, 2017), se constituyera en una fundación de caridad a la cual los hacendados afectados donaron sus propiedades en vez de ser expropiados ${ }^{29}$.

23. Web de la Oficina Regional para América Latina y el Caribe,

http://white.lim.ilo.org/spanish/260ameri/oitreg/ofireg/historia.html (9/7/2020).

24. Esta gruesa distinción iba más allá de lo puramente espacial y refería a la larga historia de los pueblos y a los niveles de integración-civilización respecto del mundo moderno. Fue un tema relevante en la Comisión de Expertos en Trabajo Indígena.

25. Hay una amplia correspondencia entre el director regional del PIA, el boliviano Enrique Sánchez de Lozada, y la sede central en Ginebra sobre el asunto. Por ejemplo, el primer informe que envió Sánchez de Lozada a Ginebra del 8.10.1953 (Archivo OIT Ginebra, TAP/AND, 2, 1) o la carta del funcionario James L. Mowat a Sánchez de Lozada del 20.01.1954 (Archivo OIT Ginebra, TAP/AND, 2, 1).

26. «Memorandum on discussion on Land for the Andean Indian Program» del 05.11.1953 (Archivo OIT Ginebra, Z, II, 10, 8, 2).

27. Carta personal del Ministro de Agricultura Nuflo de Chavez a Sánchez de Lozada del 24.11.1953 (Archivo OIT Ginebra, TAP/AND, 2 ,1).

28. Informe de los senadores estadounidenses Mansfield y Hickenlooper «Technical Cooperation in the Andes Countries of South America» del 1957.

29. Carta del jefe de la base del PIA en Pillapi, Schweng, «The unsettled state of ownership of Pillapi and its consequences» del 19.09.1955 (Archivo OIT Ginebra, TAP/A, 11-5, 1). Más detalles en Zabala Canedo (2017). 
No obstante, la colaboración del PIA con el gobierno boliviano y la reforma agraria causó preocupaciones en Ecuador y Perú. En enero de 1954, el funcionario de la OIT James L. Mowat escribió al director regional del PIA, Sánchez de Lozada, para advertir que esa colaboración podía poner en riesgo la participación de los gobiernos de Perú y Ecuador, destruyendo el carácter regional del programa ${ }^{30}$. El PIA se encontraba en una situación contradictoria entre asistir a cada gobierno nacional y lograr una misma política para los tres países: mientras que, en Bolivia, participaba en la reforma agraria, en Ecuador y Perú los gobiernos nacionales lo orientaban a evitar el levantamiento social, la revolución política y la redistribución de la propiedad de la tierra ${ }^{31}$.

Ese era el objetivo del general Odría en Perú, preocupado por la recurrente y creciente conflictividad rural en los departamentos del Sur. Jef Rens recogía la impresión de Julio Pereyra, director general de Asuntos Indígenas y alto representante del ministerio peruano, según el cual:

it is precisely in the highland areas bordering Bolivia that the Indian problem in Peru was most acute. There exists in that area a surplus population, which makes life hard and difficult. The Agrarian Reform carried out in Bolivia has become known in the neighboring Peruvian Indian tribes [sic] and unless radical action is taken to improve their lot, this region may become a core of unrest ${ }^{32}$.

La «acción radical» de Pereyra era una redistribución de la población, con un amplio proyecto de colonización de las zonas tropicales al este de la cordillera andina con colonos indígenas del Altiplano, desde Puno al valle del Tambopata. El plan de colonización no se realizó, por falta de infraestructuras y fondos, pero desde él se estructuró el PIA en Perú (Mannarelli, 2017).

En Ecuador, la puesta en marcha fue más lenta, con un proyecto de producción artesanal de textiles en Quito, pero poco después se expandió desde la base de operaciones en Chimborazo hasta convertirse en la experiencia nacional más amplia y significativa del PIA. Igual, estuvo afectada por los cambios de gobierno y régimen político, en los que la incorporación de los indígenas había ganado relevancia para la soberanía económica y, muy importante, militar (Prieto y Páez, 2017b). En todo caso, la OIT se cuidó de que se identificara al PIA con la política de redistribución de Bolivia ${ }^{33}$.

30. Carta del funcionario James L. Mowat a Sánchez de Lozada del 20.01.1954 (Archivo OIT Ginebra, TAP/AND, 2, 1).

31. Las relaciones entre los conflictos por la tierra, los poderes locales y la cuestión indígena está lejos de tener una explicación lineal y simple bajo el estereotipo del gobierno oligárquico inmovilista, en especial en el Altiplano boliviano y peruano.

32. Protocolo del encuentro entre Jef Rens y el director general de Asuntos Indígenas del Perú, Julio Pereyra, en agosto de 1954 (Archivo OIT Ginebra, Z-II-10-8-1).

33. Algunos expertos mexicanos fueron rechazados de los puestos del PIA en Ecuador y Perú por considerar la política indigenista de México demasiado «radical». Protocolo del encuentro entre Jef Rens y el Director General de Asuntos Indígenas del Perú, Julio Pereyra, en agosto de 1954 (Archivo OIT Ginebra, Z-II-10-8-1). 
Esa ambigua colaboración del PIA con la «revolución boliviana» muestra una fractura móvil dentro de la región andina sobre las estrategias de desarrollo y cambio social, bajo el continuo esfuerzo por mantener una representación colectiva para toda la región. En Bolivia, la relevancia del PIA se desgastó en la conflictiva sucesión de gobiernos. En Perú, la amplia reforma agraria del gobierno militar de Velasco Alvarado subsumió los planes de desarrollo que derivaban del PIA e integró a funcionarios indigenistas, como los antropólogos Héctor Martínez y Mario Vázquez (este último pasó a la OIT algunos años después). Y en Ecuador, el gobierno militar de Rodríguez Lara lo cerraría bajo señalamientos de «comunismo».

El tercer reto del PIA era aplicar una metodología de «carácter integral» que respondiera a su concepción sintética de indígena. Así, se procuraba que los equipos internacionales y nacionales coordinaran actividades en agricultura, salud, trabajo social, participación comunitaria y educación primaria y profesional, con el objetivo de apoyar a la población afectada de forma «integral» y mejorar su nivel de vida dentro de las sociedades nacionales ${ }^{34}$. En la práctica, esa integración de disciplinas no se logró en el grado esperado y estas tuvieron pesos distintos según países y bases de operaciones, dando lugar a un constante debate sobre los efectos que el programa tendría en el mantenimiento del carácter indígena durante su incorporación a las sociedades nacionales.

Un caso ejemplar fue la instalación de talleres de mecánica y de carpintería donde impartir formación profesional a los hombres jóvenes de las comunidades, con acceso a máquinas sofisticadas donadas por los sindicatos de los países industrializados. La formación de «capital humano», en torno a la capacitación profesional, las condiciones de vida y la organización de trabajadores, era un objetivo fundamental en la OIT (Maul, 2012 y 2019), pero su aplicación dentro del PIA puso en evidencia la gran tensión, inherente al indigenismo, entre la modernización y la reivindicación de los indígenas y de lo indígena.

Fue significativo que el gobierno de Perú cuestionara la ubicación de los talleres en lugares remotos del Altiplano, por su escaso provecho al estar lejos de centros urbanos más poblados y mejor integrados en el desarrollo económico nacional ${ }^{35}$, pese a que Puno, donde se localizaban los talleres, era un departamento central en el Altiplano, frontera con Bolivia, el Amazonas y salida a los puertos del Pacífico. El cuestionamiento mostraba una distribución espacial y cultural de las opciones de desarrollo, en la que lo indígena se desplazaba hacia el espacio rural geográfica y culturalmente «remoto» respecto del mundo urbano moderno. Desde una preocupación contraria, la antropología aplicada alertaba de que ese tipo de formación industrial alejaría a los indígenas de sus comunidades de origen. Según Juan Comas (entonces secretario del Instituto Indigenista Interamericano), los aprendices de mecánica de automóviles o los carpinteros no iban a encontrar trabajo en sus lugares de origen, con lo que su formación los llevaría a emigrar (Comas, 1959).

34. El libro coordinado por Prieto (2017) analiza varios casos que iluminan las prácticas, los diferentes actores involucrados y la perspectiva de las comunidades.

35. «Informe del Secretario General del Instituto Indigenista Peruano sobre el Programa PunoTambopata» del 13.04.1957 (Archivo OIT en Ginebra, TAP/A, 1-1, 4). 
Carlos D’Ugard, el director regional del PIA en ese momento, respondía en el periódico peruano El Comercio:

[que desde el PIA] sólo querían dar al indígena mejores armas para luchar en la vida y sacarlo de la postración en que vive, obligado a trabajar únicamente como peón. [...] Apuntó que frente a la invasión de las ciudades por los indígenas, estos ya no serán parásitos, pues podrán ganarse la vida con los oficios aprendidos y hasta podrán dar ocupación a otro en sus pequeños talleres ${ }^{36}$.

El argumento de D’Ugard apuntaba a una preocupación recurrente en el indigenismo sobre las condiciones de vida de los indígenas en las ciudades y los costos de su «inevitable» modernización, asunto que ya destacara Moisés Sáenz en los años treinta y que las ciencias sociales convirtieron en el gran debate de las sociedades andinas y mesoamericanas en los años sesenta y setenta ${ }^{37}$. Dentro del PIA, el debate sobre la formación profesional revelaba la ambivalencia del discurso sobre la «integración» y el «desarrollo» de la población indígena, pues preservar la identidad indígena y lograr la modernización e integración social de esos indígenas era un reto difícil de resolver (Comas, 1959; Martínez y Samaniego, 1978).

\section{CONCLUSIONES}

Por su envergadura y efecto representacional, el PIA solo es comparable con lo realizado por el indigenismo oficial en México y por su equivalente en Brasil. Aun así, tuvo una repercusión internacional mayor que estos dos núcleos mesoamericano y amazónico, gracias a la imbricación del PIA en la operativa de la ONU y a la proyección que la OIT dio al indigenismo latinoamericano, en especial al andino ${ }^{38}$. Las características orgánicas, la cobertura universalista y el despliegue histórico de la OIT en Latinoamérica coadyuvaron a que el PIA destacase en el proceso que las políticas de «protección e integración de las poblaciones indígenas» siguieron dentro de la OIT, desde la CIT de Montreal, 1946, hasta la medular publicación de 1953 y la adopción del Convenio 107 en 1957. Pese a lo ambiguo de los resultados, el PIA presentaba una experiencia con la que avalar su representación colectiva de América Latina, algo que la OIT destacaría en la concepción del programa, en los medios de comunicación (Breuer, 2018a) y en su propia historia institucional.

Hemos analizado el PIA desde dos aspectos constituyentes de la representación colectiva: el registro del valor representacional y las actuaciones burocrático-políticas en nombre

36. Ofrecen aplicar plan en región del Sur para dar orientación técnica al indígena. El Comercio de Lima del 23.06.1958.

37. El libro de Henri Favre (1998) El indigenismo es una buena muestra, por ser parte de esa trayectoria. También Devés (2003).

38. En la CIT de 1946, Edward J. Phelan, director de la OIT, asumió como propio el informe de Víctor Gabriel Garcés, reconocido indigenista que, en ese momento, también era miembro del Instituto Indigenista Interamericano. Esta última institución y el PIA mantuvieron una colaboración algo tensa (Martín-Sánchez y Giraudo, 2020.). 
de esa representación. Mostramos la construcción de un discurso programático, que imbricaba los textos de la planificación del PIA con la defensa del papel de la OIT en América Latina y desplegaba tres elementos fundamentales en la representación colectiva de América Latina: los indígenas y lo indígena como distinción de los Andes y de América Latina; la región como geografía humana previa y superior a los países; y las expectativas del cambio moduladas como experimento. No era una representación creada ex novo por el PIA ni la OIT, sino una adaptación de demandas y discursos muy difundidos dentro y fuera de América Latina, sobre la originalidad, integridad y novedad del subcontinente (Quijano y Wallerstein, 1992). No se trataba de mera retórica laudatoria, sino del enmarcado simbólico de la acción de la OIT en el continente, una acción que desbordaba los estrechos límites del PIA en el amplio campo de la justicia social y la internacionalización de los estándares laborales, económicos y sociales. Por ello, el esquema de retos y actuaciones no es un listado de éxitos o fracasos respecto del plan inicial, sino una muestra del poder político, burocrático y experto que, con sus muchas contradicciones, desplegó el PIA al tiempo que la OIT se postulaba como gran actor en campos sociales tan importantes en América Latina como el indigenismo, el desarrollo rural y la política de integración continental.

En nuestra perspectiva hay que interpretar la historia del PIA como realización práctica y discurso performativo en la estrategia de la OIT en América Latina, tal como el diplomático peruano Luis Alvarado Garrido (en ese momento funcionario de la OIT y luego ministro de Trabajo y Asuntos Indígenas, primero, y de Relaciones Exteriores, después, durante el segundo gobierno de Manuel Prado) anotó en una carta del 26 de mayo de 1953:

[Many] members of the staff [of the International Labour Office], especially Latin-Americans... feel that the most important project for which the Office (ILO) has taken full responsibility is the Andean Indian project which covers a whole continent and which affects not a small group of people but the whole population of several countries ${ }^{39}$. [Cursivas añadidas]

Lo interesante, al final de este análisis, es que esa estrategia contribuyó a la institucionalización política, burocrática, intelectual y jurídica de una representación, entre otras posibles, de América Latina. Al final del PIA, el aspecto diferencial más relevante, el enfoque indigenista, había perdido relevancia práctica, desplazado por el desarrollo rural y comunitario. El PIA quedaba en la arqueología de la cooperación y el indigenismo, bajo sedimentos de reformas agrarias y archivos burocráticos. Sin embargo, es fácil reencontrar buena parte de aquella representación colectiva respecto del territorio, los indígenas y la modernización en el paradigma del desarrollo rural del presente (Asensio, 2016) y, por extensión, en los imaginarios sobre la «auténtica» América Latina.

\section{BIBLIOGRAFÍA}

Anaya, S. J. (2009). International Human Rights and Indigenous Peoples. Wolter Kluwer. Arrighi, G. y Silver, B. (2001). Caos y orden en el sistema-mundo moderno. Akal.

\section{Correspondencia no ordenada (Archivo OIT en Ginebra, Z-II-10-8 2).}


Asensio, R. H. (2016). Los nuevos Incas. La economía politica del desarrollo rural andino en Quispicanchi (20002010). IEP.

Barragán, R. (2017). La geografía diferencial de los derechos. Entre la regulación del trabajo forzado en los países coloniales y la disociación entre trabajadores e indígenas en los Andes (1920-1954). En L. Caruso y A. Stagnaro (Coords.), Una historia regional de la OIT. Aportes sobre regulación y legislación del trabajo latinoamericano (pp. 25-64). Universidad Nacional de La Plata.

Bourdieu, P. (1985). ¿Qué significa hablar? Economía de los intercambios lingüísticos. Akal.

Breuer, M. (2018a). El Programa Indigenista Andino en la prensa: imágenes de lo indígena y la cooperación internacional para el desarrollo (1953-1965). Nuevo Mundo Mundos Nuevos. https://doi. org/10.4000/nuevomundo.72087

Breuer, M. (2018b). Exploring the technical assistance activities of the ILO in the field of indigenous peoples. Development and Human Rights in the Andean Indian Programme (1954-1968). Forum for Interamerican Research, 11(3), 110-123.

Caruso, L. y Stagnaro, A. (Coords.) (2017). Una historia regional de la OIT. Aportes sobre regulación y legislación del trabajo latinoamericano. Universidad Nacional de La Plata.

Castel, R. (2004). Las metamorfosis de la cuestión social. Paidós.

Comas, J. (1959). La misión andina y la aculturación indígena. América Indígena, 19(3), 169-177.

Devés, E. (2000). El pensamiento latinoamericano en el siglo XX. Entre la modernización y la identidad, tomo 1. Biblos-Dibam.

Devés, E. (2003). El pensamiento latinoamericano en el siglo XX. Entre la modernización y la identidad, tomo 2. Biblos-Dibam.

Eco, U. (1998). Los limites de la interpretación. Lumen.

Escobar, A. (2012). Encountering development. The making and unmaking of the Third World. Princeton University Press.

Favre, H. (1998). El Indigenismo. Fondo de Cultura Económica.

Ferguson, J. (1990). The Anti-politics Macbine. Development, Depoliticization and Bureaucratic Power in Lesotho. Cambridge University Press.

Giraudo, L. (2011). Un campo indigenista transnacional y «casi profesional». La apertura en Pátzcuaro (1940) de un espacio por y para los indigenistas. En L. Giraudo y J. Martín-Sánchez (Coords.), La ambivalente historia del indigenismo. Campo interamericano y trayectorias nacionales 1940-1970 (pp. 21-98). IEP.

Gobat, M. (2013). The Invention of Latin American Historical Review. A Transnational History of Anti-Imperialism, Democracy, and Race. American Historical Review, 118(5), 1345-1375.

Guthrie, J. (2015). The International Labor Organization and the Social Politics of Development. 1938-1969. Disertación, University of Maryland.

Herrera León, F. y Herrera González, P. (Coords.) (2013). América Latina y la Organización Internacional del Trabajo. Redes, cooperación técnica e institucionalidad social, 1919-1950. Universidad Michoacana de San Nicolás de Hidalgo, Universidad de Monterrey, Universidade Federal Fluminense.

Jolly, R., Emmerj, L., Ghai, D. y Lapeyre, F. (2004). UN contributions to development thinking and practice. Indiana University Press.

Kott, S. (2018a). La justice sociale dans un monde global. L'organisation internationale du travail (1919-2019). Le Mouvement Social, 2(263), 3-14.

Kott, S. (2018b). Towards a Social History of International Organisations. The ILO and the Internationalisation of Western Social Expertise (1919-1949). En M. B. Jerónimo y J. P. Monteiro (Coords.), Internationalism, Imperialism and the Formation of the Contemporary World (pp. 33-57). Palgrave Macmillan.

Lechner, N. (1986). La conflictiva y nunca acabada construcción del orden deseado. CIS/Siglo XXI. 
Mannarelli, M. E. (2017). La Misión Andina en Puno, Perú. El estado y lo doméstico. En M. Prieto (Coord.), El Programa Indigenista Andino 1951-1973. Las mujeres en los ensambles estatales del desarrollo (pp. 163-234). FLACSO, IEP.

Mansfield, M. y Hickenlooper, B. B. (1957). Technical Cooperation in the Andes Countries of South America. Report to the Senate Committee on Foreign Relations.

Martín-Sánchez, J. (2017). The review Informaciones Sociales: The ILO and Argentina in the Latin-Americanization of the social question in the 1920s. En R. González Leandri y J. Suriano (Coords.), The Social Issue and Its Itineraries of Dissemination Through Argentine Periodicals: 1870-1930 (pp. 203-229). Globalsouth.

Martín-Sánchez, J. y Giraudo, L. (2020). De la «race indigène» à l'essentialisme pratique : le rapprochement de l'Institut indigéniste interaméricain et de l'Organisation internationale du travail (1940-1957). Critique International. Revue comparative de Sciences Sociales, 86, 45-65.

Martínez, H. y Samaniego, C. (1978). Política indigenista en el Perú. 1946-1969. En Centro Latinoamericano de Trabajo Social (Coord.), Campesinado e Indigenismo en América Latina. CELATS.

Maul, D. (2012). Human Rights, Development and Decolonization. The International Labour Organization, 1940-70. Palgrave Masmillan.

Maul, D. (2019). The International Labour Organization. 100 Years of Global Social Policy. De Gruyter Oldenbourg.

Maurel, C. (2011). Le Programme indien-andin des Nations Unies (années 1950-1960). Cabiers des Amériques Latines, 67, 137-161.

Max-Neef, M. A. (1992). From the outside looking in. Experiences in 'barefoot economics'. Zed Books.

Misión Andina. (1953). Informe de la misión conjunta de las Naciones Unidas y los organismos especializados para el estudio de los problemas de las poblaciones indígenas andinas, tomo I. OIT.

OIT. (1953). Poblaciones indígenas. Condiciones de vida y de trabajo de los pueblos autóctonos de los paises independientes. OIT.

Poblete Troncoso, M. (1928). Labour legislation in America Latina I. International Labour Review, 17(1), 51-67.

Poblete Troncoso, M. (1938). Condiciones de Vida y de Trabajo de la Población Indigena del Perú. OIT.

Prieto, M. (Coord.) (2017). El Programa Indigenista Andino 1951-1973. Las mijeres en los ensambles estatales del desarrollo. FLACSO, IEP.

Prieto, M. y Páez, C. (2017a). El Programa Indigenista Andino. Integración-desarrollo, estado y mujeres indígenas. En M. Prieto (Coord.), El Programa Indigenista Andino 1951-1973. Las mujeres en los ensambles estatales del desarrollo (pp. 5-50). FLACSO, IEP.

Prieto, M. y Páez, C. (2017b). La Misión Andina en Ecuador: doble delegación femenina y sentidos de estado. En M. Prieto (Coord.), El Programa Indigenista Andino 1951-1973. Las mujeres en los ensambles estatales del desarrollo (pp. 111-162). FLACSO, IEP.

Quijada, M. (1998). Sobre el origen y difusión del nombre «América Latina» (o una variación heterodoxa en torno al tema de la construcción social de la verdad). Revista de Indias, 58(214), 596-615.

Quijano, A. y Wallerstein, I. (1992). Americanity as a concept, or the Americas in the modern worldsystem. International Social Science Journal, 134, 549-557.

Rens, J. (1959). Latin America and the International Labour Organisation. Forty Years of Collaboration 1919-1959. International Labour Review, 80(1), 1-25.

Rens, J. (1987). Le Programme Andin. Contribution de L'OIT à un Projet-Pilote de Coopération Technique Multilatérale. Établissements Émile Bruylant.

Rodríguez-Piñero, L. (2005). Indigenous Peoples, Postcolonialism, and International Law. The ILO Regime (1919-1989). Oxford University Press.

Said, E. (2008). Orientalismo. Random House Mondadori. 
LA OIT Y LA DEFINICIÓN DE AMÉRICA LATINA COMO REGIÓN DE CARÁCTER ESPECIAL: EL PROGRAMA INDIGENISTA ANDINO ENTRE LA CUESTIÓN INDÍGENA Y LA MODERNIZACIÓN UNIVERSALISTA

Stein, W. (2010). Repensando el discurso andinista. SUR.

Weinberg, P. D. (Coords.) (2019). La OIT en América Latina: los orígenes de una relación. Fundación de Cultura Universitaria.

Zabala Canedo, M. L. (2017). La Misión Andina y las mujeres en Pillapi, Bolivia. Disputas y dinámicas ambiguas. En M. Prieto (Coord.), El Programa Indigenista Andino 1951-1973. Las mujeres en los ensambles estatales del desarrollo (pp. 51-110). FLACSO, IEP. 